\title{
THE IMPACT OF PRODUCTION STRUCTURE ON INCOME DISTRIBUTION: A MULTIPLIER APPROACH
}

\author{
Maria J. F. Willumsen*
}

\section{Introduction}

Distributional issues have increasingly asserted themselves as a major concern of economic analysis. Since production structure is believed to be a very important element to affect income distribution, technology and its impact on employment creation have also gradually gained importance as a policy instrument.

Based on standard behavioral models of profit maximization or constrained cost minimization, which predict that more labor-intensive techniques would be used in less developed countries (LDC's), the microeconomic literature has emphasized the 'paradox' of inappropriate choice of technology in these countries, and its possible connection with the distribution of income. ${ }^{1}$ Two facts give support to this concern. First, in the last decades several developing countries (including Brazil) experienced a visible shift in their production structure towards the manufacturing sector (Chenery, Robinson and Syrquin, 1986, p. 77) and the use of more capital intensive technologies (Chenery, Robinson and Syrquin, 1986. p. 21). Second, this change in the structure of production was accompanied by a visible worsening in the distribution of income. Since capitalintensive technologies are believed to be biased against the generation of wages ${ }^{2}$ (Sen, 1967; Suntcliff, 1971; Furtado, 1976; Ranis, 1977; Weaver, 1980; Thorbecke, 1988), some authors have related the use of 'inappropriate' capitalintensive technologies to the deterioration in the distribution of income.

In spite of numerous microeconomic studies in the area of choice of technology (Boon, 1975; Ranis, 1977; Tokman, 1978; Svejnar and Thorbecke, 1983), very few empirical studies have been conducted at the macroeconomic level. The incorporation of technology within a comprehensive and intersectoral framework and the study of the impact of alternative technologies or production structure on income distribution has often been neglected. ${ }^{3}$

The purpose of this paper is to examine the relationship between production structure and income distribution as well as to evaluate the implications of a given technological choice or output-mix to the income received by

\footnotetext{
*Assistant Professor of Economics, Florida International University, Miami, Fl. The author gratefully acknowledges the contributions of three anonymous referees.
}

different socio-economic groups in Brazil. The paper is organized as follows. Section II discusses the data framework and the structure of the model. Section III develops the multiplier analysis, and section IV concludes.

\section{Data Framework and Structure of the Model}

The analytical framework adopted for such an analysis is the Social Accounting Matrix (SAM). SAMs incorporate not only technical aspects of production, which are commonly dealt with in input-output models, but also social aspects of production, that is, the underlying social and institutional structure of the economy in question. Accordingly, this framework is capable of revealing the links between sectors and classes; how the earnings of one class (or socioeconomic group) are spent in some other sector or industry. Those interindustry and intersectoral relations are crucial to understanding how the distribution of income is established and maintained, and how changes in demands or in technology transform themselves into affluence for some and deprivation for others. Relating income distribution to different patterns of linkages, payment streams, and technological dependency between industries, sectors, and classes leads to a different vision of how the economy works. This view places emphasis on the interdependence of production rather than of markets; technical and institutional interlocks rather than purely market relationships, in sharp contrast with the orthodox view of the economy in which technology is the sole determinant of income distribution.

As general equilibrium frameworks, SAMs are capable to integrate these factors in a consistent way and constitute, therefore, an appropriate analytical tool to investigate the issues addressed here.

The model is explicitly based on the Social Accounting Matrix (SAM) for Brazil, calibrated for the year 1975 (Willumsen, 1984). Factors, households, and production activities- are assumed to be endogenously determined; government, capital and rest of the world are assumed to be given. Table 1 presents the structure of the model as applied to Brazil.

Notation and definitions corresponding to each endogenous submatrix shown in Table 1 are as follows: $\mathrm{V}_{\mathrm{aj}}=$ value added generated in activity jaccruing to factor s; 


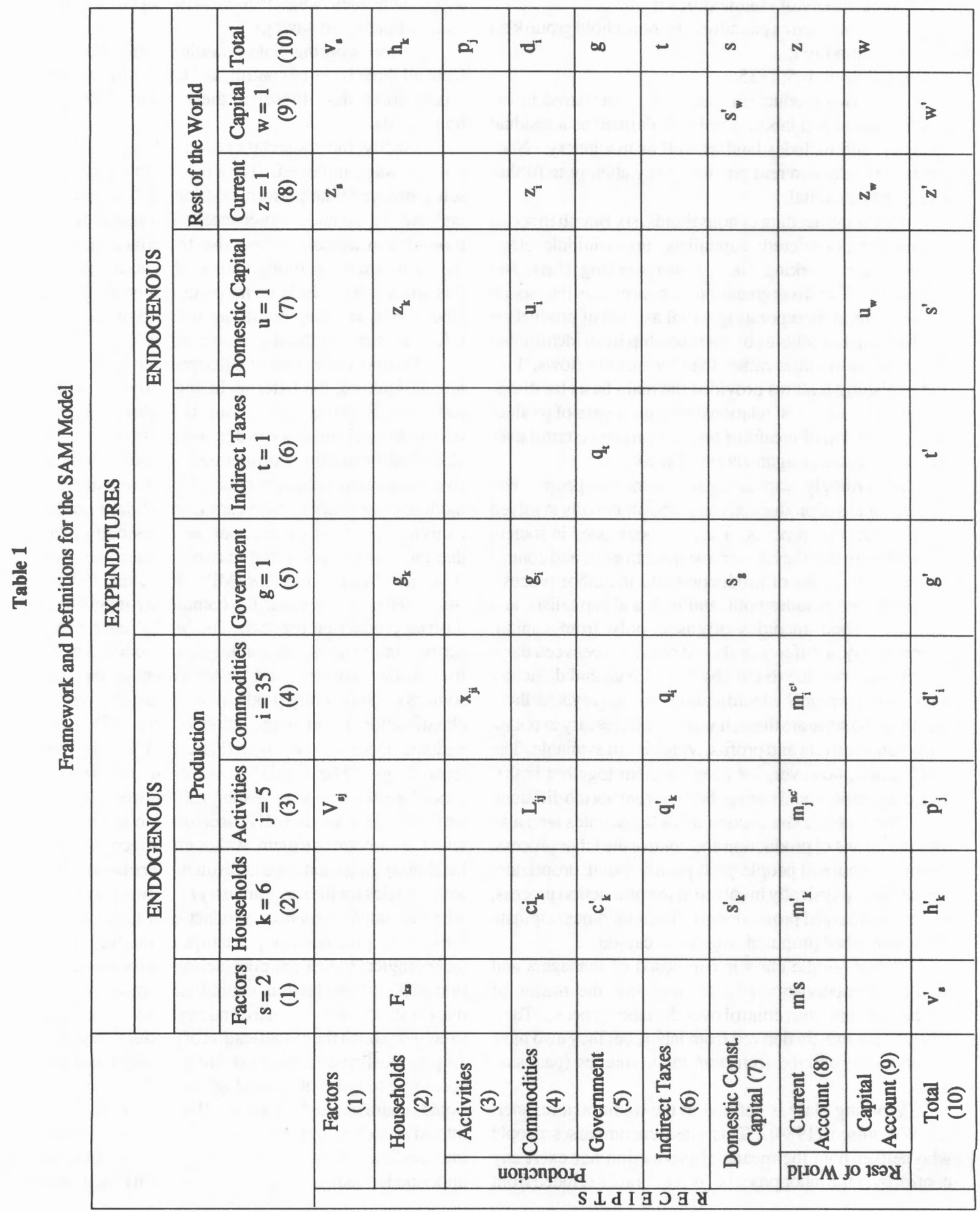


$\mathrm{F}_{\mathrm{ks}}=$ factorial income $\mathrm{s}$ accruing to household group $\mathrm{k}$;

$\mathrm{L}_{\mathrm{ij}}=$ intermediate demand by industry $\mathrm{j}$ for commodity $\mathrm{i}$;

$X_{i j}=$ total supply of commodities $i$;

$\mathrm{C}_{\mathrm{ik}}=$ consumption expenditures by household group $\mathrm{k}$ on commodity i;

where $s=2 ; k=6 ; j=5 ; i=35$.

Only two production factors are considered in the model: capital and labor. Capital is defined as a residual category, and includes land as well as machinery. Nonexistence of data on rent precluded any attempt to further disaggregate capital.

Under the heading of households, six Brazilian social classes are considered: capitalists, upper-middle class, middle class, working class, lower-working class, and underclass. The disaggregation of households into social classes aims at incorporating social aspects of production and labeling households by membership in an identifiable cluster of individuals rather than by income flows. Two distinguishing features provided the main basis for disaggregating households: relationship to the means of production (ownership of means of production) and control over the labor process (organization of work).

Accordingly, capitalists are defined as people who own the means of production and are not materially involved in the production process. They are positioned in society in such a way that they determine investments, and control the physical means of production and the labor process. This category includes both landlords and capitalists, and rentiers. Their incomes originate only from capital. Theoretically, a difference should be drawn between these two classes, but due to the absence of data and difficulty with their empirical identification, we aggregated them together. To separate them, it would be necessary to obtain information on rent and profits, which is not available. The justification, however, for keeping them together is that their consumption and savings behavior are not toodifferent.

The middle class encompasses households who also own the means of production and control the labor process. Here two groups of people are typically found: proprietors who are also physically involved in the production process, and self-employed professionals. Their incomes originate from both labor (imputed wage) and capital.

Upper middle class is composed of managers and high-level supervisors who do not own the means of production, but exert control over the labor process. Their incomes are mostly derived from labor, but they also have a component derived from non-labor sources (past savings).

Working class is defined in the traditional manner, see Willumsen (1984). This class encompasses people who neither own the means of production nor exert any control over the labor process. Workers are excluded from all three kinds of control (over investment, means of production and labor). They work for a wage, but may also supplement their wage income with capital income as a result of their past savings.

Lower-working class households are also excluded from all three types of control, and their working skills are much lower than those of the regular working class households.

Finally, the underclass is defined as people who are not formally employed. They belong to the category of self-employed who perform odd jobs as "domestic workers" and "repair and maintenance". The absence of formal training and education, and also the erratic character of their jobs are the defining traits of this class. Workers in this stratum have little or no participation in the regular labor force, and they constitute the core of the so-called informal sector of the Brazilian economy.

Production sectors are grouped into agriculture and non-agriculture, the latter including activities other than just manufacturing. Agriculture is further disaggregated into traditional and modern agriculture; non-agriculture is classified into traditional, intermediate and modern. These five production sectors produce 35 heterogeneous commodities. In order to take care of secondary production (activities producing more than one commodity), the production sector is presented in two matrices, the so-called 'Use' and 'Make' matrices (Miler and Blair, 1985). The 'use' matrix $\left(\mathrm{L}_{\mathrm{ij}}\right)$ records the commodity inputs to an industrial production process. The 'make' matrix $\left(\mathbf{X}_{\mathrm{jij}}\right)$ describes, in the rows, the commodities produced by industries in the economy and, in the columns, the industry sources of commodity production. In fact, the production classification is an aggregation of the 1975 Brazilian national input-output table (FIBGE, 1987) by type of technology. The crucial question in this aggregation procedure was how to distinguish between production activities, at least partially, according to the technology which is embodied in them. Although we recognize that the ideal disaggregation should distinguish between different technologies for the same industry or commodity produced with alternative techniques (product-cum-technology), data limitations precluded any attempt to do so. ${ }^{4}$ A set of technological indicators, considering the form of organization, scale of production, capital/labor ratio, control and market structure - by sector and firm size- was prepared to help establish the classification of production activities. ${ }^{3}$ As previously indicated, production activity is categorized according to types of technology in three groups: a) traditional, characterized by its small-scale operation, laborintensive technology and more competitive markets; b) intermediate, whose characteristics are to some extent undefined, making it impossible to classify them into any 
one of the other two categories; c) modem, characterized by large-scale operation, use of capital-intensive technology, and dominance of multinational corporations and oligopolistic markets.

The adopted classification for Brazilian production is presented here, in a way that the key to translation from commodities to activities is evident.

Activities

1. Traditional Agric.

2. Modern Agric.

3. Traditional Non-Agric.

5. Modern Non-Agric.
Commodities

1. Vegetable, Extraction, Hunting and Fishing

2. Coffee and Cocoa Cultivation

3. Other Agriculture

4. Livestock Excepting Poultry

5. Mining and Quarrying

6. Soybean, Sugar and Wheat Cultivation

7. Poultry Raising

8. Petroleum and Gas

9. Stone, Clay, Glass, and Concrete Products

10. Lumber and Wood Products, except furniture

11. Furniture

12. Leather Products, Wearing Apparel, and Footwear

13. Food Manufacturing

14. Beverage

15. Other Manufacturing

16. Contract Construction

17. Repair and Maintenance Services

18. Wholesale and Retail Trade

4. Intermediate Non-Agric. 19. Textile Manufacturing

20. Editing and Publishing

21. Hotel, Motel, Restaurant Services

22. Metal Industries

23. Machinery, except Electrical

24. Electric Machinery

25. Passenger Transportation

26. Paper Manufacturing

27. Rubber Products

28. Chemicals, Pharmaceuticals, Cosmetics

29. Plastic Products

30. Tobacco Manufacturing

31. Industrial Services

32. Social Services

33. Hauling Transportation of Commodities

34. Communication, Financing and Advertising

35. Imported Products
The core around which the empirical model is built is an input-output table for Brazil, which provides a picture of the pattem of interrelatedness among productive units. For a detailed discussion of the input-output relationships see Willumsen (1984). The identification of distinctive types of economic activities, incorporating different technologies, allows the integration of commodity relationships with broader analyses which emphasize not only the technical but also social relationships of production. The inclusion of households (disaggregated by social classes) as an endogenous element in the model, closes the system and provides a picture of the circular flow of income in the economy.

Accordingly, incomes (value added) which are generated in the production sector (input-output matrix, expressed in matrix $L_{i j}$ ) are paid to factors (factorial income distribution, expressed in submatrix $\mathrm{V}_{\mathrm{s}}$ ), which in turn pay households (institutional income distribution, recorded in matrix $F_{k}$ ). Finally, households spend their incomes in consumption of goods (recorded in $\mathrm{C}_{\mathrm{ik}}$ ), closing the loop. Profits are assumed to be directly paid to households, since companies are not explicitly treated in the model.

These flows thus contain all elements of the interdependent system and also express the technical and behavioral relationships needed to close the model in a consistent way. All these relationships are assumed to be linear, which implies the use of Leontief-type production functions and fixed coefficients for the factorial and institutional distributions of income, as well as for the consumption behavior of different social classes (unitary income elasticities). Also implicit is the assumption of constant prices, which holds true only if excess capacity exists in the economy.

One of the implications of using linear coefficients is that the endogenous part of the model becomes a matrix of average propensities. This matrix is presented in Table 2, in which the submatrix $A_{n}$ records the average propensities for outlays and incomes of endogenous variables, while the submatrix $A_{1}$ represents the average propensities for the leakages in the system. The exogenous variables are expressed in the submatrices $\mathrm{T}_{\mathrm{nx}}$ (injections) and $\mathrm{T}_{\mathrm{xx}}$ (residual balances), where $\mathrm{T}$ stands for the actual values of expenditures, in contrast with the average propensities expressed in the As submatrices.

We now have all necessary elements to proceed with a formal representation of the model. Accordingly, the incomes for the endogenous accounts are determined by

$$
\mathrm{y}_{\mathrm{n}}=\mathrm{n}+\mathrm{x}
$$

where $\mathrm{n}$ denotes expenditures by endogenous variables, and $x$ represents expenditure by exogenous variables (expressed in $T_{n n}$ and $A_{m}$ ). Incomes of exogenous accounts are

$$
y_{x}=1+t
$$




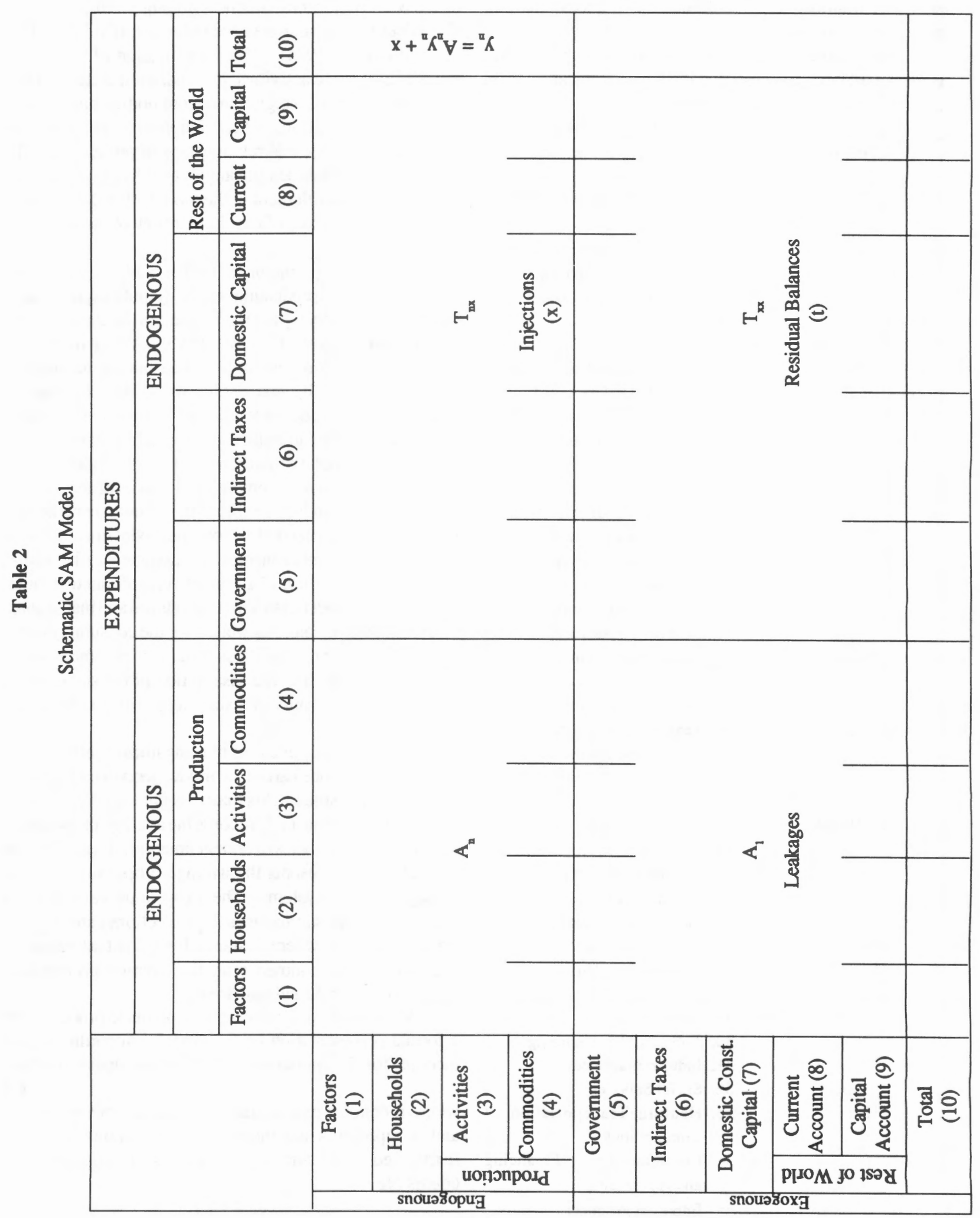


where 1 and $t$ are, respectively, expenditures by endogenous and exogenous accounts. Since $A_{n}$ and $A_{1}$ are matrices of average propensities,

and

$$
\mathrm{n}=\mathbf{A}_{\mathrm{n}} \mathbf{y}_{\mathrm{n}}
$$

$$
1=\mathrm{A}_{1} \mathrm{y}_{1}
$$

Expression (1) now can be rewritten in a more appropriate way. Combining equations (1) and (3) we obtain the equation for the determination of incomes for endogenous accounts:

Provided that $(\mathbf{I}-\mathbf{A})^{-1}$ exists

$$
\begin{aligned}
& y_{n}=A_{n} y_{n}+x \\
& =\left(I-A_{n}\right)^{-1} x
\end{aligned}
$$

Substituting (7) in (6)

$$
(I-A)^{-1}=M_{\text {a }}
$$

$$
y_{n}=M_{a} x
$$

The latter equation (8) shows that incomes for endogenous accounts $\left(y_{n}\right)$ can be obtained by multiplying the injections $(x)$ by $\left(M_{2}\right)$, the so-called multiplier matrix (Round, 1980).

The literature refers to this matrix as the accounting multiplier matrix, since it explains the results observed in the model and not the process by which they are generated. These multipliers, as derived from a linear model, are characteristically static and, consequently, essentially shortterm in nature. To describe the process which generates the corresponding results over time would require the specification of a dynamic model, connecting its different variables and describing their behavior. The building of such a model, however, is a complicated undertaking in view of the difficulties associated with trying to explain investment determination, technological change and the operation of the labor market. For now, we shall rely on the accounting multipliers to proceed with our analysis and investigate some macroeconomic effects of alternative technologies or output-mix.

\section{Multiplier Analysis}

Kahn (1931) produced the pioneering analysis of multipliers, and up until the late 1930's they were primarily used to examine the relationship of changes in investment to changes in income and its connections with business cycles. However, the introduction of the concepts of marginal propensity to consume (MPC) and to save (MPS) by Keynes (1936) provided the turning point in impact analysis. After Keynes contribution, a series of works by Samuelson (1939), Chipman (1959), and Stone (1978) to list only the first and most representative ones- incorporated extensions to the framework in order to derive other types of multipliers.

The recent development of the SAM-type models by Pyatt and Thorbecke (1976) and Pyatt and Round (1979) opened new perspectives for multiplier analysis. Since these models are explicitly based on an accounting framework and maintain considerable detail in their production and institutions accounts, they provide support for enlightening analyses. They allow the discussion of multipliers to be rendered not only within the traditional context of 'changes in the system', but also - and especially - in terms of structural analysis (Pyatt and Roe, 1979; Dafourny and Thorbecke, 1983; Sonis and Hewings, 1988). It is mostly within this latter context that we perform this empirical investigation, undertaking the analysis by means of a static framework, with emphasis on the examination of structural relationships between production and income distribution.

Traditionally, the accounting multipliers derived from this type of model are interpreted as a measurement of response to a unit of change in any exogenous variable (final demand). Therefore, following the closure of the model with respect to households, they represent the total impact (direct, indirect and induced) on the system, resulting from any external change.

Our present analytical interpretation of multipliers for Brazil is slightly different from this traditional approach, in the sense that we will use the accounting framework, which underlies the model, to trace incomes arising from alternative expenditures (such as potential final demand for different output-mix). By equating the notion of 'influence' with that of 'expenditures' (Lantner, 1974), we are then able to follow the transmission of economic influence within the given structure and to evaluate it by means of multipliers. This structural analysis attempts to clarify and explain, to some extent, the solution of the model. Through the study of the transmission of influence within the network of structural relations, one can start with changes in exogenous variables and follow them until their ultimate effects on endogenous variables.

Although the triangular interrelationship (production, factors, institutions) of the endogenous structure of this SAM implies that any path must move in a triangular direction, it should be noted that the selected pole of origin, within a SAM structure, can be in any of the three endogenous accounts. Furthermore, as suggested by Pyatt and Round (1979), the analysis can be performed by means of any of the decomposed multiplier effects. ${ }^{6}$

Since the objective of this paper is to evaluate the impact of different production structures on income distribution, our empirical analysis will focus on the production sector as the origin of changes and the social classes as its destination 'pole'. Given that the classification of 'production sector' is intended to be a means of splitting incomes derived from different technological structures, and the disaggregation of factors of production is meant to obtain equivalence between factorial and institutional income 
distribution, the link between production structure and distribution of income is readily established. We are then at the point of embarking on the empirical analysis.

To do so we focus on two submatrices of the large multiplier matrix. The first submatrix is formed by five columns (representing activities embodying distinct technologies) and two rows (representing factors). This matrix, depicted in Table 3 portrays the factorial income distribution (distribution of value added, by activity, into labor and non-labor income). For a detailed analysis, see Willumsen (1984).

According to these results, one may see that all economic activities in Brazil, unambiguously, generate more capital income than labor income. Within each category of income, however, the impact differs slightly. In the generation of labor income, for instance, traditional non-agriculture is the most important one, with a multiplier of 0.75 , followed by agriculture (both traditional and modem with a multiplier of 0.65 ). Intermediate and modernnon-agriculture $(0.63$ and 0.60 , respectively) comes next. Regarding non-labor income, a different outcome may be detected: the sector with the highest impact on the generation of non-labor income is traditional agriculture (1.19), followed by modern agriculture (1.09). Intermediate non-agriculture, traditional non-agriculture and, finally, modern non-agriculture, showing multipliers of 1.04 , 0.92 , and 0.82 , respectively, are the other ones.

These results are not in accordance with expectations generated by the works mentioned above (Sen, 1967; Suntcliff, 1971; Furtado, 1976; Ranis, 1977; Weaver, 1980; Thorbecke, 1988). As a matter of fact, one would expect to see traditional activities as the leading sector in the generation of labor income. This is not the case here. On the contrary, the discrepancy in the distribution of factorial income between labor and capital is higher in traditional agriculture than in any other activity $(0.65$ for labor against 1.19 for capital). Khan and Thorbecke (1988 p. 66) also recognize it when they write that "somewhat surprisingly, comparing the traditional and modern activ- ity within each pair of product-cum-technology, it does not appear that the modern technology generates more total capital income than the corresponding traditional technology." This fact is partially due to the happening that traditional technology tends to generate more rent going to land than the modern technology for the aggregate capital as defined in this work. This becomes evident in the analysis above, where we found that traditional Brazilian agriculture generates higher capital income multiplier than the modem one. Since traditional agriculture is known to be more landintensive than modern agriculture, the higher capital income multiplier is certainly affected by that. This, however, does not explain the whole story. If one looks at the nonagriculture sector, where capital does not include land, the same results hold. Unambiguously, capital income multipliers are higher than labor income multipliers, no matter the type of technology.

The next step in the analysis is to examine how these results affect the distribution of income among different social groups. Table 4 depicts a submatrix for Brazil originated from the multiplier matrix $\mathrm{M}_{\mathrm{a}}$ and is composed of the same columns dealt with above (1 through 5 , which represent production activities) and five different rows (referring to social classes). This table records the multipliers expressing the impact of different production structures (technologies) on household incomes.

Two alternative (but not mutually exclusive) ways of looking at this submatrix offer different perspectives to analyze the issues in question. The reading of multipliers along the rows (varying columns 1-5) provides information on how different technologies affect a given social class. For instance, for each social class, one can read along the rows and obtain information on which structure of production benefits most this given group. Two levels of structural differences can be explored in this context: a) between sectors, that is, between agricultural and nonagricultural sectors; and b) within these two sectors, i.e., differences between modern and traditional activities in each sector (agriculture and non-agriculture). Accord-

Table 3

Multipliers for the Factorial Income Distribution

\begin{tabular}{llllll}
\hline \hline & $(1)$ & $(2)$ & $(3)$ & $(4)$ & $(5)$ \\
\hline Labor & 0.65 & 0.65 & 0.75 & 0.63 & 0.60 \\
Non-labor & 1.19 & 1.09 & 0.92 & 1.04 & 0.82 \\
\hline \hline
\end{tabular}
where
(1) = Traditional Agriculture
(2) = Modern Agriculture
(3) = Traditional Non-Agriculture
(4) = Intermediate Non-Agriculture
(5) $=$ Modern Non-Agriculture 
Table 4

Open Loop Multipliers for Household Incomes

(1)

\begin{tabular}{ll} 
Capitalists & 0.50 \\
Upper Middle Class & 0.21 \\
Middle Class & 0.54 \\
Working Class & 0.24 \\
Lower Working Class & 0.19 \\
Underclass & 0.08 \\
\hline & \\
\hline (1) $=$ Traditional Agriculture \\
(2) = Modern Agriculture \\
(3) = Traditional Non-Agriculture \\
(4) = Intermediate Non-Agriculture \\
(5) = Modern Non-Agriculture
\end{tabular}

ingly, Table 4 indicates that for capitalists and middle class the activity with the highest impact is traditional agriculture, with multipliers of 0.50 and 0.54 respectively. Modem agriculture generates the next highest impact on these classes, followed by the other non-agricultural industries -intermediate, traditional and modern, cited in descending ranking order. For upper-middle class the ranking of multiplier effects is consistent with the one just discussed, although their impact is much lower. The ranking changes for the other classes. For working class and lower working class, the ordering of multiplier effects is similar: first comes the traditional non-agriculture sector as the one which generates more income to these groups; after this one, traditional and modern agriculture follows. Intermediate and modern non-agriculture are the last ones in terms of multiplier effects.

Two interesting facts can be noticed when examining these multipliers. The first one is that for each class these multipliers lie between a quite narrow range of magnitudes. Contrary to what was expected, for every class and regardless of the type of technology utilized, the magnitude of multipliers along the rows (incomes of a given class) is minimal. The interpretation of this result is not straightforward. It may, however, be suggesting that the impact of technology on incomes of different groups is not as important as one would expect. The other observation refers to the fact that incomes of capitalists and middle class are more positively affected by traditional technologies than modern ones, especially in agriculture. Given that these two classes are composed of people who own the means of production and have their incomes constituted mainly by profits, one would expect that traditional activities would not exert such a positive impact on them because these activities are, "supposedly", the ones to benefit workers the most.
The reading of multipliers along columns (and thus across the rows) enlightens the discussion of the impact generated by a given technology. Again, the analysis may be performed at two different levels. The first one allows for the evaluation of the impact of a given technology on total income of households. Within this context, the most general finding is that in both agricultural and non-agricultural activities, traditional sectors yield a higher income multiplier than modern ones. Accordingly, while the total income multiplier for traditional agriculture is 1.76 , for the modem agriculture sector it is only 1.67. By the same token, traditional activities in the non-agriculture sector originate higher total income multiplier (1.62) than modem activities in the same sector (1.36).

At a more specific level, the multipliers in Table 4 permit one to investigate how a given technology affects different social classes. Thus, by fixing the production sector (and consequently technology), one can read the multipliers down the columns and grasp information on who benefits most, in terms of income, from a given production structure (technology or choice of output-mix). That is to say, one is able to capture the relative power of these groups in appropriating income generated in the economy.

The most visible information one can get from the data (Table 4) is the nonexistence of homogeneity in the magnitude of multipliers along the columns. Diverging completely from the pattem shown in the analysis performed along the rows (across columns), the size of multipliers, in this case, vary within a wide range of amplitude. For instance, traditional agriculture generates income multipliers that range from 0.54 for the middle class to 0.08 for the underclass. For modern agriculture the amplitude is very similar, while for modern non-agriculture the discrepancy is less accentuated; in this case, the highest 
multiplier is 0.39 , for middle class, and the lower is 0.07 , for underclass. This outcome holds true for all sectors. As a matter of fact, for whichever technology one considers, household incomes differ greatly among classes. The visibility of such a pattern is not restricted to the strength of the multiplier effects. Their ranking, too, follows a discemible configuration. Capitalists and middle class are the ones most benefited from all sectors/or technologies. These groups are followed, then, by working class, uppermiddle class, lower working class and finally underclass. Whether we consider a more traditional production sector or a more modern one, the ordering of the income multipliers is the same: only their size will change.

\section{Interpretation of Results}

The results obtained in this work for Brazil are important. The analysis performed here was meant to identify two forces at work in the distribution of income. The first one refers to the importance of technology and its effect on income distribution by social classes. This analysis was accomplished by examining the multiplier along the rows and evaluating the impact of different technologies on a given class. The results obtained indicate that technology does matter for income distribution. In this regard, we verified that for whichever class one considers, traditional technology has a more positive impact on that class, in terms of income, than a more modem technology. Its impact, however, does not appear to be as strong as one would expect.

Considering the second motif of investigation, that is, the examination of importance of classes for the distribution of income, the results are more interesting. The analysis, as explained before, was performed by inspecting the multipliers along the columns (across rows). By fixing a technology (or sector), one can examine which class would benefit best from it. The outcome of such an analysis reveals a pattern of multipliers that are consistently large for certain classes. In the Brazilian case, capitalists and middle class, for instance, always benefit more than any other class, no matter the type of technology. The fact that these two classes are the ones who benefit most from a given technology indicates that classes do count in the distribution of income. If we turn back to the defining characteristics of social classes utilized in this work, we are able to identify some attributes common to these two classes which may help to interpret the results. In this specific case, they both encompass people who own the means of production. One could argue, however, that the high income multipliers in Brazil for the classes embodying owners of the means of production (capital) could be interpreted as an indication of the scarcity of capital and surplus of labor, a characteristic of most developing countries. This is conceivably part of the explanation for such high multipliers, which could be reflecting high rental rates. The capacity utilization rates prevailing in the economy during that year $(0.87)$, however, much below the rates of previous years $(0.94-0.97) \mathrm{cannot}$, alone, be responsible for such high multipliers. The importance of ownership for the distribution of income is not a novel idea. It dates from Marx and has been a theme for discussions since then. Oscar Lange (1970), among others, observed that capitalism is intrinsically unable to distribute income in a fair way because income distribution is determined by the distribution of ownership of the means of production and that is not fairly distributed. Nell (1987) also agrees with such an approach by arguing that the ownership of means of production confers advantages, though not absolute ones, in the setting of prices (mark-up pricing) and in bargaining for money wages. Exactly what these advantages are, how they work, by what kinds of forces -are among the questions which a theory of distribution should explore.

The results obtained in this work for Brazil are also in accordance with Wright's (1985) empirical investigation on the relationship between class structure and income distribution. In that work, he verified that incomes vary monotonically along the dimensions of exploitation, the latter defined in terms of social relations built around the ownership or control of different elements of forces of production: labor power, capital, organization of work, and skills or knowledge as proposed by Roemer (1983). When the control over these assets gives people effective claims on the social surplus, exploitation takes place. Although our work does not explicitly deal with exploitation, to the extent that we are claiming that classes - which are delineated on the basis of property relations-do matter in the distribution of income, we are implicitly relating class to exploitation and income distribution. In this connection, our results attach some credibility to the exploitationcentered (property-centered) concept of class defended by Roemer, who demonstrates the existence of a strict correspondence between class location, exploitation status and the quantity of assets owned by individuals.

\section{Concluding Remarks}

The results commented on above must be taken and interpreted with caution. On one hand, they should not be easily generalized, because they refer to a specificeconomy (Brazil) and to only one point in time (year of 1975). Since the nature of impacts evaluated by the multipliers lead to structural changes in the matrix of coefficients, only a dynamic model can properly assess the long-run effect of 
changes in technology. On the other hand, they should not be disregarded either, because they uncover some issues that have been overlooked in economic analysis.

Although the implications of such findings are not straightforward, they suggest, however, that factors other than just technical ones (expressed in the coefficients of the input-output table) might be playing an important role in the process of income distribution. As a consequence, they imply that the socially conditioned character of general economic categories and relationships must be further explored. The recognition of households categorized by social classes (property relations) rather than by income brackets or occupations, as usually treated, seems to be an appropriate classification to analyze income distribution. By not taken the economic system as given, the model seems to be capable of capturing some structural features of the economy that may be playing an important role in the distribution of income.

The disclosure of the importance of class structure in the process of income distribution is a non trivial result. It suggests that the model, by not taking the economic system as given, is capable of capturing certain structural features of the economy (class structure) that are not apprehended in most models which deal with the study of income distribution.

From a policy perspective, the implications of the results obtained in this work are of no less importance. They suggest that there may be no significant trade-off between modernization and employment or income distribution. Policies pursuing a better distribution of income, therefore, will have to exploit instruments other than purely economic ones, such as technology choice.

\section{Notes}

'The "paradox" is expressed in the deviation from the specialization postulated by the factor endowment principle, which would predict that those countries, which experience surplus labor, would specialize in labor-intensive sectors/technologies.

${ }^{2}$ Capital-intensive technologies are, a priori, believed to be biased against wages because they are supposed to generate high returns on capital (which, in developing countries is scarce). Since capital represents the largest share among factors of production utilized, profits are expected to be much higher than wages.

3Gupta (1977), Adelman and Robinson (1978), Taylor, Bacha, Cardoso and Lyzy (1980) have modeled the behavior of factor markets, production, and income distribution, but their models have not explored the effects of technology on income distribution. A recent work by Khan and Thorbecke (1988) is an attempt to explore, in a macro framework, such a relationship.

4Since the purpose of this research is to examine the relation- ship between production structure and income distribution, at the macro level, and not to identify "appropriate" techniques within a given sector, this limitation does not compromise the results obtained in this study.

5For a detailed analysis of the structure of the Brazilian production sector, see Tavares (1986).

The decomposition of multipliers allows for the evaluation of the impacts of an exogenous shock into other elements of the same block (intragroup or direct effects); other elements in the system, without being fed back to the sector where it has originated (extragroup or open loop effects); or still sectors other than the ones where they originated (crossed or closed loop), but in this last case feeding back to the pole of origin.

\section{References}

Adelman, I., and S. Robinson. Income Distribution Policies in Developing Countries: A Case Study of Korea. Stanford, CA: Stanford University Press and World Bank, 1978.

Boon, G. K. "Technique Choice in Metalworking with Special Reference to Mexico". In A.S.Bhalla(ed.). Technology and Employment in Industry. Geneva: International Labor Office, 1975.

Chenery, H., S. Robinson and M. Syrquin. Industrialization and Growth: A Comparative Study. New York: Oxford University Press, 1986.

Chipman, J.S. "The Multi-Sector Multiplier". Econometrica. 18 (1950). 355-74.

Dafourny, J. and E. Thorbecke. "Structural Path Analysis and Multiplier Decomposition within a Social Accounting Matrix Framework". Economic Journal. 94 (1983). 111-134.

Furtado, C. Economic Development of Latin America. Cambridge University Press, 1976.

Gupta, S. "A Model for Income Distribution, Employment and Growth: A Case Study for Indonesia". World Bank Occasional Paper. Baltimore: John Hopkins University Press. No. 24, 1977.

Kahn, R. F. "The General Relationship of Home Investment to Unemployment". Economic Joumal. (June 1931).

Keynes, J. M. The General Theory of Employment, Interest, and Money. Hartcourt, Brace and World, Inc., 1964.

Khan, H. A., and E. Thorbecke. Macroeconomic Effects and Diffusion of Alternative Technologies Within a Social Accounting Matrix Framework. London: Gower Publishing Co., 1988.

Lantner, L. Theorie de la Dominance Economique. Paris: Dunod,1974.

Lange, O. Sobre la Teoria Economica del Socialismo. Barcelona: Ediciones Ariel, 1970.

Miller, R., and P. Blair. Input-Output Analysis, Foundations and Extensions. Englewood Cliffs, NJ: Prentice Hall, 1985.

Nell, E. "Economics: The Revival of Political Economics". In 
Alternatives to Economic Orthodoxy (eds.) R. Albelda, C. Gunn, and W. Waller. New York: M. E. Sharpe Inc., 1987.

Pyatt, G., and J. Round. “Accounting and Fixed Price Multipliers in a Social Accounting Matrix Framework". The Economic Journal. 89 (December 1979). 850-873.

and E. Thorbecke. Planning Techniques for a Better Future. Geneva: International Labor Office, 1976.

Ranis, F. "Industrial Technology Choice and Employment: a Review of Developing Country Evidence". Interciencia. 1977.

Roemer, J. A General Theory of Exploitation and Class. Cambridge, Mass.: Harvard University Press, 1982.

Samuelson, P. "The Balanced Budget Multiplier: A Case Study in the Sociology and Psychology of Scientific Discovery". Collected Scientific Papers. Cambridge, Mass.: The MIT Press, 1974. 641-853.

Sen, A. Choice of Technologies. New York: Oxford, 1968.

Sonis, M., and G. Hewings. "Superposition and Decomposition Principles in Hierarchical Social Accounting and Input Output Analysis". Mimeo, University of Illinois at UrbanaChampaign, 1988.
Suntcliff, R.B. Industry and Development. New York: AddisonWesley Publishing Co., 1971.

Svejnar, J., and E. Thorbecke. "Determinants and Effects of Technological Choice in Developing Countries". In B. Lucas (ed.). Internal and Extemal Constraints on Technological Choice in Develóping Countries. London: TooleyBowker Publishing Co., 1984.

Tavares, M. C. Acumulacao de Capital e Incustrializacao no Brasil. Campinas, SP: Editora Unicamp, 1986.

Taylor, L., E. Bacha, E. Cardoso, and F. Lyzy. Models of Growth and Distribution for Brazil. New York: Oxford University Press, and World Bank, 1980.

Tokman, V. "Distribucion del Ingreso, Tecnologia y Empleo. Un Analisis del Sector Industrial del Ecuador, del Peru y Venezuela. Trimestre Economico. 164 (1978).

Weaver, F. Class, State, and Industrial Structure. New York: Greenwood, 1980.

Willumsen, M. J. F. The Social Accounting Matrix as a Tool for Policy Analysis: The Case of Brazil. Unpublished Ph.D. dissertation, Cornell University, 1984.

Wright, E. O. Classes. London: Verso, 1985. 